Debra D. Chapman, Peter Eglin

Wilfrid Laurier University, Canada

\title{
"The Machines Don't Lie": A Study of the Social Production of Mechanization in the Determination of Voter Intent
}

DOI: https://doi.org/10.18778/1733-8077.10.2.03

Abstract Because election results are the essential measure of the popular will in liberal democracies, accurate determination of voter intent is a necessary pre-requisite since "what $[\mathrm{N}]$ does is not simply make a mark on a piece of paper; he [sic] is casting a vote" (Peter Winch). If every vote counts, then every valid vote must be counted - which means seeing the mark on the paper as intentional action. But, electronic voting systems are increasingly used in Canada. Given the operational vagaries of the use of such machines, the paper asks: How is voter intent mechanically achieved as a practical, social accomplishment of the human beings charged with working the machines and counting the votes? The paper then reports a case study of the tallying of ballots in one municipality in a recent Ontario municipal election where the official result between the two top candidates was a difference of one vote. It focuses on the social production of mechanical consistency in the determination of voter intent during the recount process.

Keywords Ethnomethodology; Ethnography; Voter Intent; Electronic Voting; Machines; Mechanization; Counting; Practical Reason

Debra D. Chapman, PhD, is currently a member of the Contract Academic Staff in Political Science, North American Studies and Global Studies at Wilfrid Laurier University, Waterloo, Ontario. She employs ethnography in studies of popular opposition to neoliberal globalization in Mexico and Latin America generally (The Struggle for Mexico: State Corporatism and Popular Opposition [2012]), and more recently of international service learning, global citizenship, and human rights. Her research and teaching are informed by an abiding concern for social justice

email address: debchapman@golden.net
Peter Eglin, PhD, is a Professor of Sociology at Wilfrid Laurier University, Waterloo, Ontario. As a student of ethnomethodology, Wittgensteinian sociology, and conversation analysis he investigates the use of categories for describing persons in practical reasoning in talk and texts. He is a collaborator on Dr. Debra Chapman's research project on international service learning, global citizenship, and human rights. He is incensed by the ongoing ruination of the universities under neoliberalism, fears for human survival under global warming, and seeks liberation from capitalism and strong states: see his Intellectual Citizenship and the Problem of Incarnation (2013).

email address: peglin@wlu.ca
Tf the purpose of voting is to determine the will of the electorate, then the reliability and validity of the methods used to measure the electorate's will become practical issues for those bodies charged with administering elections in electoral democracies. These matters have been much discussed in the professional and academic literature on the conduct of elections. We do not propose here to review either body of work, but to focus attention on what is perhaps a neglected, though in our view fundamental, dimension of such deliberations. This is the matter, after ethnomethodology (Garfinkel 1967; 2002), of the irremediable dependence of any judged-to-be-reliable and valid electoral outcome on the practical, interactional means by which in any actual instance that outcome is achieved. In the present case, we wish to take advantage of an unusual circumstance in which one of the authors had participatory access to an election in which the winning margin was a single vote. The resulting two recounts, both of which confirmed the original result, afforded an opportunity for gaining an ethnographic view of the practical procedures used to determine voter intent in terms of both the reliability and validity of the counting methods used. We wish to focus particularly on the methods used by the counters-as-vote-determiners to achieve identical results across the three counts, even more particularly on how the final manual recount eventuated in the same outcome as the previous two counts produced by the optical scanning tabulators. We call this outcome the "mechanization" of voter intent, an outcome we analyze as a practical, interactional (and therefore human, social) achievement of the parties involved. ${ }^{1}$

$\frac{{ }_{1} \text { Three things make the particular election under investigation }}{\text { here noteworthy- First there was a one-vote difference between }}$ the leading candidates; second, the ballots were tallied using
Electronic voting systems (EVS) are increasingly used in Canada. Because election results are the essential measure of the popular will in liberal democracies, accurate determination of voter intent by EVS is a necessary pre-requisite. "The notion that voters can expect to have their preferences recorded accurately and fairly is fundamentally important in a democracy" (Dee 2007:681). For just this reason, the mechanization of voting has come under critical scrutiny. Regarding testing of electronic machines, Balzarotti and colleagues (2010) state that "while current standards provide a 'checklist' of characteristics that must be verified, there are no guidelines or suggestions on how these characteristics can or should be verified" (p. 454).

Reliability of the counting procedure is one thing, its validity another. After all, "what $[\mathrm{N}]$ does is not simply to make a mark on a piece of paper; he [sic] is casting a vote" (Winch 2008:46). Voting is observably an intentional action in the context of certain political institutions, those say, of parliamentary democracy. In Searle's (1969) terms, a vote is an institutional fact, not a brute one. If every vote counts, then every vote that is a vote must be counted - which means seeing the mark on the paper as intentional action.

Whereas the reliability of a measuring device is the extent to which it produces the same result when

optical scanning tabulators; third, there were two recounts following the announcement of the Election Day results. The results of the study were used to recommend changes to out-of-date aspects of the Ontario Municipal Elections Act, including further suggestions on how to ensure that all votes are counted. These recommendations and suggestions are reported else-
where (Chapman 2012). The authors wish to thank Professor Robert Williams for his thorough and able critique of the manuscript of that paper, the lessons of which have been carried into this substantially amended and variant version. 
measuring the same thing on different occasions, the validity of a measuring device is the degree of confidence the measurer can have that the device actually measures the phenomenal property in question, however reliably it produces the same result on different occasions (Eglin 1987:195). For example, in the case of voting, it may be that the adopted method of counting ballots produces the same result on successive counts of the "same" ballot; the method is reliable, it may be said. But, it may also be the case that the adopted method miscounts the ballot in question by repeatedly mistaking for whom the voter intended to vote. For municipal election managers (deputy returning officers [DROs], city clerks), the validity problem typically arises when the voter's mark on the ballot does not conform to the rules. It falls outside the circle or box, for example, or consists of a mark that is not the prescribed "X." In "Is the Ballot Valid or Invalid?" Mr. W. D. (Rusty) Russell, Q. C. (1980) provides a particularly thorough account of the variety of problematic marks that have been used on ballots in municipal elections in Canada and of the legal grounds on which determinations have been made by the courts of what the voter intended in specific cases.

He reviews the problematic cases under four headings, namely, the position of the mark, the type of mark, the presence of other marks, and the marking instrument used. He reports that the "paramount" legal consideration is "fulfilling the voter's intention," and the primary disqualification is, interestingly enough, that the voter's mark should identify the voter. His account makes reference to a variety of commonsense explanations of errant marks that are entertained more or less in passing - poor eyesight (particularly among senior citizens), illiteracy, "nervousness, misunderstanding and confusion," drunkenness, unsteadiness of hand, changing one's mind (Russell 1980:232). These are treated in effect as reasonable excuses for inaccurate marking of the ballot that should not, in themselves, be sufficient to invalidate the ballot.

Finally, Russell (1980) worries that the delicate parsing of legal judgments should be beyond the capacities of DROs:

[i]t is one thing for me to report the decisions of judges learned in the law as to what is and what is not, a valid ballot (even the court interpretations are not consistent). It is quite another thing on how a Returning Officer should instruct the deputy returning officers on their statutory duties in the polling place. Certainly, they cannot get too technical. (p. 232); [f]rankly, it is a near impossible task to teach deputy returning officers the sophistication of these "judgment calls" of the court. (p. 237)

In a footnote thanking a particular city clerk for his comments on a draft of the article, he writes, "[n]othing quite equates the experience of an old pro' who knows the practical side of the problem" (Russell 1980:237). In line with this view of distributed expertise is the 1874 opinion of Lord Neaves recommending the virtue of the cross as a suitable mark: "[i]t is, I think, a mark well devised for the purpose, easy of execution by men of the most moderate intelligence" (Russell 1980:235). And underlying all these considerations is the sine qua non of Western jurisprudence, the presupposition of the "reasonable man" (sic). Thus, Mr. Justice Maclennan of the Ontario Supreme Court in 1898: [i]f a ballot is so marked that no one looking at it can have any doubt for which candidate the vote was intended and if there has been a compliance with the provisions of the Act according to any fair and reasonable construction of it, the vote ought to be allowed. (Russell 1980:234, emphasis added)

The above rehearsal of the range of practical circumstances and background assumptions acknowledged as being taken into account in the legal and logistical determination of voter intent for the purpose of counting ballots as between competing candidates for electoral office is not meant to bring into doubt the validity of a foundation stone of electoral democracy, albeit at the municipal level. On the contrary, what we wish to bring out is the inevitability of the recourse to just such practical matters in the determination of valid ballots and reliable counts in every actual case. It is just such taken-for-granted, seen-but-unnoticed recourse to the ad hoc practices of practical reasoning that holds up the whole edifice of electoral democracy as an institutional, social fact, and therefore, as an object for sociological inquiry: "[t]he objective reality of social facts is sociology's fundamental phenomenon" (Durkheim as cited in Garfinkel 2002:65). The point being made here is the cardinal ethnomethodological insight made long before by Garfinkel in his Studies in Ethnomethodology (1967):

[t]o treat instructions as though ad hoc features in their use were a nuisance, or to treat their presence as grounds for complaint about the incompleteness of instructions, is very much like complaining that if the walls of a building were only gotten out of the way one could see better what was keeping the roof up. (p. 22)
The particular point we will take up in the Discussion section is the method of practical reasoning employed by the city clerk in the election in question to standardize its outcome across three counts. It is a rule that may be glossed with the phrase “the machines don't lie."

\section{The Technical Background: Electronic Voting Machines}

Balzarotti and colleagues (2010:453) remind us of a quote that has been attributed to Stalin and which states, "those who cast the votes decide nothing. Those who count the votes decide everything."2 Of course, this was stated prior to the use of electronic voting machines. With the current voting methods, one could add that blind confidence in voting machines gives decision making powers to machines and not the elector on the assumption that it is the machines that decide everything (Chapman 2012). The dynamic is similar in that in both cases agency is taken from the elector and placed on the counter, whether the counter is a person or a machine. Much of our purpose here is, following Wittgenstein, to assemble reminders that what the machine is seen to have counted is the product of persons' decisions; it is through and through a social outcome. Mechanization is a social production.

The idea of a secret paper ballot dates back to 1888 in Australia (Balzarotti et al. 2010:45). In the 1930s, mechanical lever machines were introduced. The 1960s welcomed punch card machines. Direct recording

${ }^{2}$ There is no primary source for this assertion, though it is be-
lieved that he said it in an unpublished speech or private conversation. It is fitting for the argument being developed here. 
electronic machines were first used in the mid-1970s. Since then optical scanners, Internet, voice activated, mail-in, telephone, and touch screen voting have come to be used. It is not that one has replaced the other. In some cases, a variety of the different methods have been used in the same province, municipality, or region. ${ }^{3}$

There has been much concern about voting procedures and tallying since the 2000 U.S. Presidential election in Florida when hanging and dimpled chads created uncertain results. More recently, in a congressional election in Sarasota County, Florida in 2006, the Election Day results found "17,846 ballots (14.9 percent of the total number of votes) cast on electronic voting machines showed no vote for either candidate in the race" (Balzarotti et al. 2010:453). Again, in 2008 in Minnesota, there were almost 7,000 ambiguous ballots challenged in a senatorial race. In so far as electronic voting systems are being widely adopted, then these U.S. examples call into question current election methods around the world.

There are numerous studies of the reliability and virtue of different voting methods (AMCTO 2011), the influence of voting methods on voter turnout (Card and Moretti 2007; Allers and Kooreman 2009), the reliability and security of electronic systems (Balzarotti et al. 2010), and whether residual votes increase or decrease depending on the method used (Mebane 2008). For example, Lott (2009) makes an

${ }^{3}$ In a letter from the president of the Association of Municipal Managers, Clerks and Treasurers of Ontario (AMCTO) to the
then Minister of Municipal Affairs and Housing, Kathleen then Minister of Municipal Affairs and Housing, Kathleen the likelihood of municipal electors having newer technologies available for voting. important observation about so-called under-votes. He questions whether non-votes or under-votes "are intentional or the result of problems using the voting machines" (Lott 2009:171-172). If the Dominion optical scanner used in the Midwest municipal election could not read the markings on the ballot, because they were outside of the box or because the marking did not cover at least $25 \%$ of the box, then they would be registered as under-votes. One very thorough study of Diebold optical scanning machines (Hursti 2005) goes so far as to examine technical aspects of the scanners and the irregularities found in the memory cards of these machines.

The study being reported here differs from, yet complements, those referred to above. As a Canadian case study of voter intent and recount procedures at the municipal level, it does not examine the technical function of the machines, but is concerned with the procedural aspects of the use of the machines. As Balzarotti and colleagues (2010:455) state, "electronic voting systems [are] far from being the final solution to voting problems. In fact, technology alone does not guarantee the absence of irregularities or problems."

\section{Method}

In methodological terms, the subject of investigation here is addressed through a partially ethnographic case study of the tallying of ballots in Ward 9 in the City of Midwest, Ontario in the 2010 municipal elections. The study examines aspects of the Ontario Municipal Elections Act, official court and City documents, selected studies of election procedures, and observations made during the count- ing/recounting of the ballots. The court documents come from the Ontario Superior Court of Justice, Court File \#C-1016-10, [Name] versus the Corporation of the City of Midwest, which documents are accessible at the City of Midwest Ontario Superior Court of Justice. Because it permits the investigator "to observe and collect rich and detailed information about [a setting], which cannot be collected using the standard interview methods" (Hughes and Sharrock 2007:221), participant observation of the recount process was used to complement the official data sources drawn on for the study. The data collected through observation are the most valuable component of the analysis presented here, given that access to the process was limited to the City Clerk, the candidates for the ward in question, one scrutineer for each tabulator/polling station, one lawyer per candidate and one for the City, an Assistant Recount Officer for each machine, and the media (whose interest was to record the reaction of the candidates and report the official results) (City of Midwest Nov. 3, 2010). ${ }^{4}$

\section{The Formal Legal and Organizational Context}

Throughout the province of Ontario, 444 municipal elections were held on October $25^{\text {th }}$ 2010. Municipal election processes fall under the Ontario Municipal Elections Act (MEA), 1996, a provincial act that grants the (municipal or city) clerk the responsibility of conducting local elections (see Section 11.1 of the MEA). We focus on the city clerk's powers and

${ }_{4}^{4}$ In order to ensure full disclosure, it should be noted that Chapman participated in the electoral recount process as the losing candidate (Candidate B below). responsibilities in the election of the councilor for Ward 9 in the City of Midwest, Ontario.

As detailed in Section 11. (2) of the MEA, the clerk is responsible for:

a. Preparing for the election;

b. Preparing for and conducting a recount in the election;

c. Maintaining peace and order in connection with the election; and

d. In a regular election, preparing and submitting the report described in subsection 12.1 (2) (said report details "the identification, removal and prevention of barriers that affect electors and candidates with disabilities").

The clerk has legislated powers to determine the logistical operationalization of the election rules set out in the MEA and its accompanying regulations. He/She will determine such things as whether a composite or a separate ballot will be used (41. [4]), and "shall, (a) establish procedures and forms for the use of, (i) any voting and vote-counting equipment authorized by by-law, and (ii) any alternative voting method authorized by by-law" (42. [3]). In fact, according to Section 12.1, "[a] clerk who is responsible for conducting an election may provide for any matter or procedure that, (a) is not otherwise provided for in an Act or regulation; and (b) in the clerk's opinion, is necessary or desirable for conducting the election." While this section of the Act already gives the clerk discretionary powers 
that supersede those of the elected councilors, with the proviso that the "use of voting and vote-counting equipment such as voting machines, voting recorders or optical scanning tabulators" must be authorized through a by-law passed by municipal council (42. [1]), the AMCTO recommends that

the innovative capacity of municipal clerks [be recognized] by placing the authority of deciding on vote casting and counting methods and advance voting days with an official who is without a conflict of interest on this matter - shifting from the incumbent council to the municipal clerk such authority. (Gatien 2012)

The AMCTO suggests an amendment to the MEA that would "clarify...the breadth of the clerk's duties/responsibilities as it relates to election administration." Clearly, there is every reason to suppose that the responsibility for conducting an election that is efficient and secure and that provides for the reliable and valid counting of ballots falls heavily on the shoulders of the City Clerk.

On June 19, 2006 By-law 2006-135 was passed in Midwest, which stipulated that "[t]he use of voting and vote-counting equipment such as voting machines, voting recorders or optical scanning vote tabulators is hereby authorized in respect to the municipal elections to be held in 2006 and in subsequent election years."

It was in keeping with this by-law that voting tabulators were used in the 2010 municipal elections in Midwest. ${ }^{5}$ Voting tabulators/optical scanners were leased, programmed, and serviced from Dominion Voting, ${ }^{6}$ a multi-national corporation originating in Toronto and currently based in Denver, Colorado.

The ballot contains sections for all the offices being filled. There is a section for the Regional Chair, Regional Councilors, City Mayor, City Councilors, School Board Trustees, and two referendum questions, that is seven votes in all. Ballots are marked with black felt pens provided at the polling stations. The elector is required to place an " $\mathrm{X}$ " in the box, or fill in the box, beside the candidate of their choice, and then take the completed ballot to the machine operator who feeds the ballot into the optical scanning tabulator, facedown. While the MEA does not detail the machine jargon, the tabulators are programmed to distinguish between proper votes, over-votes, under-votes, and ambiguous ballots.?

The following is an idealized or formalized account of the counting process as it was designed for and supposed to happen in Midwest.

(1) If the ballot is "properly" filled out, the machine accepts the ballot and the process concludes.

ducted by the AMCTO (with a participation rate of over 110 used paper ballots: 15 used touch screen machines: 54 used mail-in ballots; 23 used vote by phone; 28 used vote by Internet; 3 used other (AMCTO 2011:11); and 49 used a combination of two or more of the above mentioned method (AMCTO 2011:33).

${ }^{6}$ Diebold, the subject of Hursti's study on tabulator memory cards, was bought by Dominion in 2010. Hursti made some im portant observations about the security lacunae in the storage

7 In the U.S., the concept of "residual votes" is used to refer
to "those ballots for which "no vote can be recorded" 2007:674). These are similar to ambiguous ballots but can also be over-votes. They "can be due to an error, or to an intention-
ally invalid, or blank vote" (Allers and Kooreman 2008:163).
(2) If the ballot specifies that the elector is, say, allowed to vote for 4 school board trustees and the elector votes for fewer than 4 , the tabulator registers this as an under-vote and counts all the markings on the ballot, including the section that is under-voted. In this case, the machine accepts the ballot and the voting process is complete.

(3) If the ballot is "incorrectly" filled-out, then the machine beeps and spits the ballot back out. There are two scenarios that can cause a ballot to be questioned or indeed rejected by the machine.

(3a) If the voter selects too many candidates in one of the sections of the ballot, then the tabulator notifies the voter and the operator that there is an over-vote. At this point, the operator is to turn to the voter and notify him/her that they have over-voted on some part of the ballot. The voter is then given the option to re-cast their ballot. If the voter rejects the offer, the operator presses the override button (button \#2) and the ballot is fed into the machine. When the results are tabulated, all sections of the ballot, with the exception of the over-voted section, are tabulated. This happens if, for example, the voter selects 5 school trustees instead of the allotted 4 , as per the example in (2). If the elector accepts a new ballot, the old one is placed in Envelope A with "cancelled" written on it. ${ }^{8}$

(3b) There are several circumstances in which the machine rejects ballots, returning them to the machine operator. For example, if the deputy returning

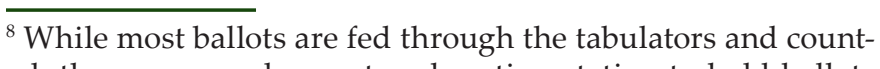
ed, there are envelopes at each voting station to hold ballots that are not counted. Envelope $\mathrm{A}$ is for cancelled or spoiled ballots, Envelope B is for declined ballots, and Envelope $\mathrm{C}$ is for ambiguous ballots. officer's (DRO) signature is illegible, the machine will reject it. Torn or damaged ballots are also rejected. Markings that cover the barcode along the side of the ballot can also result in a rejected ballot. In order for a marking to be considered a vote, it has to cover "at least $25 \%$ of the box" (Clerk's Affidavit 2010) beside the candidate's name. In these cases, the operator cannot override the machine. A ballot that is rejected by the machine for any of the aforementioned reasons becomes an ambiguous ballot and needs to be redone or corrected in order to be counted. If the voter refuses to recast the ballot, then it automatically becomes a declined ballot.

Declined ballots are not replaced or remade. They are placed in Envelope B. According to the DRO's handbook (City of Midwest Oct. 25, 2010:6.2), ballots are "declined" when the "voter deliberately declines the ballot at tabulator or the original ballot had an ambiguous mark and the voter declined to mark a new ballot." It is important to note that the second option ("original ballot had an ambiguous mark and the voter declined to mark a new ballot") does not refer to the voter declining to vote but rather declining to "mark" a new ballot. We take this up below.

Thus, ambiguous ballots are ballots that are not recognized by the machine. These non-recognized ballots are placed in Envelope C, for ambiguous ballots. Ambiguous ballots can be replaced and the elector may then mark a new ballot, which is then fed into the tabulator. If the elector chooses not to mark a new ballot, then the ballot becomes a declined ballot and is put in Envelope B. Declined ballots are not counted because the machine cannot read them. 
(4) A final category is that of spoiled ballot. A ballot is "spoiled" when "the voter has spoiled their ballot through error or made an unintentional mark on the ballot and wishes a new one" (City of Midwest Oct. 25, 2010:5.5). Spoiled ballots are never fed into the machine. The DRO writes "cancelled" on the ballot and issues a new blank ballot to the elector. The cancelled ballot is placed in Envelope A.

\section{Results}

\section{The Count on Election Day in Midwes}

The voting day process will first be discussed, followed by the two recounts that were realized shortly after the publication of the election results. The voting process is important because the legislation states (section 60. [1]) that if there is to be a recount, it must be "conducted in the same manner as the original count, whether manually or by vote-counting equipment." This means that if the original count was by mechanical means, but the candidate requested a manual recount, all the city council can approve is a mechanical recount using the same vote-counting equipment. When it comes to procedures, Section 52 of the MEA makes no reference to the particular election procedures or terminology used on October $25^{\text {th }}$ 2010. Sections 52.(3) and 52.(4) read as follows:

\section{Marking ballot, etc.}

52. (3) On receiving the ballot from the deputy returning officer, the elector shall,

a. make a cross or other mark on the ballot, within the space designated for the marking of the ballot to the right of the name of each candidate for whom the elector wishes to vote (or, in the case of a by-law or question, to the right of the answer for which he or she wishes to vote);

b. fold the ballot in a manner that conceals its face; and

c. return the folded ballot to the deputy returning officer. [1996, c. 32, Sched., s. 52 (3); 2002, c. 17 , Sched. D, s. 19 (2)]

\section{Deposit in ballot box}

52. (4) On receiving the ballot from the elector, the deputy returning officer shall immediately deposit it in the ballot box, in the full view of the elector and any persons described in clauses 47 (1) (b), (c) (d), and (e) who are in the voting place. [1996, c. 32, Sched., s. 52 (4)]

On October $25^{\text {th }}, 2010$, the actions of the DRO and the electors in Ward 9, Midwest, were not in keeping with these sections of the MEA. Instead, the process as predetermined by Dominion was adopted by the clerk who chose to use the Dominion tabulators on Election Day. Furthermore, Section 54.1 details the counting of the votes in the following way:

\section{Counting of votes}

54. (1) Immediately after the close of voting on voting day, the deputy returning officer shall open the ballot box for his or her voting place and proceed to count, (a) in the case of an election for office, the number of votes for each candidate;

(b) in the case of an election to obtain the assent of the electors to a by-law, the number of votes in favor of the by-law and the number opposed to it; and

(c) in the case of an election to obtain the opinion of the electors on any question, the number of votes for each possible answer to the question. [1996, c. 32, Sched., s. 54 (1)]

The process stipulated in this section of the Act also does not describe how the voting machines were used to count the ballots in the election in question. Thus, for example, once the polls closed in Midwest, the operator pushed a button and a cash register type tape was produced with the totals of all the offices being filled. The ballot boxes were not emptied, nor were the ballots removed and counted. While the City of Midwest approved the use of voting machines in 2006, no by-laws or amendments to the MEA were made detailing the new procedures. The DRO's Handbook details the steps to be followed by adopting the language used by Dominion, such as over-vote, under-vote, and ambiguous ballot. These different types of ballots are not identified as such in the MEA.

\section{The Particular Case of "Declined" Ballots}

Decline appears once in the Act under section 52. (1) 5, titled "Voting Procedure," which states (emphasis added):

5. An elector is no longer entitled to vote if, after receiving a ballot, he or she leaves the voting place without returning the ballot, or declines to vote and returns the ballot. [1996, c. 32, Sched., s. 52 (1); 2002, c. 17, Sched. D, s. 19 (1); 2009, c. 33, Sched. 21, s. 8 (24)]

Similarly, at the provincial level, according to the Ontario Elections Act, ballots are declined when:

53. An elector who has received a ballot and returns it to the deputy returning officer declining to vote, forfeits the right to vote and the deputy returning officer shall immediately write the word "declined" upon the back of the ballot and preserve it to be returned to the returning officer and shall cause an entry to be made in the poll record that the elector declined to vote. [R.S.O. 1990, c. E.6, s. 53]

In both of these acts, decline gives agency directly to the elector who either walks out carrying the ballot or returns the ballot to the election official without voting. The DRO's handbook, however, defines declined ballots in two senses - one where the voter deliberately declines the ballot as above, and one where the voter declines to remark a new ballot. In the second case, when referring to declined ballots with voting machines, voter agency is lost. A ballot is here defined as declined when the voter refuses or declines to remake the original ballot. Here, it is the machine that effectively creates this category of declined ballot, not the elector. The remaking or marking of a new ballot is the relevant action here. As confirmed by the Midwest City Clerk in the court hearing on December $16^{\text {th }}, 2010$, the act of not redoing the ballot is the act of declining the ballot. The elector had the opportunity, but did not take it, and therefore they declined the ballot, he argued. 
It is not unreasonable to suppose, however, that there are circumstances in which an elector might feel reluctant to remake a ballot that they considered to be their vote. As far as they were concerned, they had voted and they expected it to be counted. A person originally from a country where election fraud is the norm could be understandably disinclined to re-vote. Somebody in a hurry on their way to work could also walk away and say, "Sorry, I don't have time to redo my vote." It is not at all clear in such circumstances that the elector declined to vote. As far as they were concerned, they had voted.

In practice, it turned out on Election Day that a third category of "declined" ballots was produced. This possibility arises from a further technical feature of the electronic counting process. If the machines break down during Election Day, completed ballots are set aside in what is called the auxiliary ballot box. As stipulated in the DRO's Handbook, when the polls close, all ballots found in the auxiliary ballot box are to be fed into the tabulating machine. If any of these ballots are illegible when fed into the machine after the poll has closed, they automatically become declined ballots because the elector is unavailable to remake the ballot.

McMenemy (1995) describes the standard concept of the declined or rejected ballot when he states,

a ballot may officially be "rejected" by an elector and so recorded, as an act of protest. Otherwise, ballots cast will be tabulated as valid or declared "spoiled" if the elector's preference is unclear or the ballot is not marked in a way designated as acceptable. (p. 8)
The machine-determined "declined" ballot does not fit the "rejected" ballot category because it is not the result of an act of protest. It is more accurate to consider them "spoiled" because the elector does not clearly mark the ballot. However, if the ballot comes to be labeled ambiguous because the DRO's signature is missing or illegible, the elector's actions do not in and of themselves result in a spoiled ballot. To state that a ballot is unclearly marked means different things if the interpreter is a person rather than a machine. This idea will be further elaborated below.

The election results for city councilor in Ward 9 in Midwest, Ontario on October $25^{\text {th }}, 2010$ produced a one-vote difference between the winning candidate and the next candidate. From here on in, the winning candidate will be referred to as Candidate A, the second placed one as Candidate B.

\section{The First Recount}

On October $27^{\text {th }}$, two days after the election, Candidate $B$ submitted a request to the city clerk for a manual recount. Recounts can come about in three ways. The first is through a request to city council, the second is a judge ordered recount, and the third is a judicial recount. If requested through city council, the process is as follows (as quoted in relevant part):

\section{Recount for municipality, local board or Minister}

57. (1) Within 30 days after the clerk's declaration of the results,

(a) the council of a municipality may pass a resolution requiring a recount of the votes cast, (i) for all or specified candidates for an office on the council,

(ii) for all or specified answers to a question submitted by the council,

(iii) for and against a by-law submitted by the council.

Section (60), as detailed above, stipulates that the recount must be conducted in the same manner as on Election Day. In the case in question, Midwest City Council approved the request for a recount, but was bound by the Act to make it a mechanical recount, as this was the manner of the original count. In the event this required the emptying of all ballot boxes and the feeding one by one of all ballots into the tabulators. Scrutineers for all candidates and lawyers were invited to witness the recount.

Unlike the process on Election Day if, during the recount, the tabulators did not now accept ballots they had accepted on that day, these ballots were inspected by the candidates, the clerk, and the lawyers and then remade. On Election Day, these ballots would have been considered ambiguous and the elector would have been given the opportunity to re-vote. At the recount the elector was not in the room or available to remark the ballot, so the clerk exercised his authority to remake the ballot for the elector, with the approval of the candidates present. This is an example of the inability of the machines to replicate the electoral process of Election Day without human intervention. Some of the ballots that were rejected by the machine had clearly been damaged/torn from the transportation of the ballot boxes. However, there were 3 ballots that appeared to be without damage. The clerk explained that in one case the DRO's signature was not dark enough, and that in the second case the markings had crossed into the barcode on the ballot causing it to be illegible. The third ballot looked properly completed to all concerned. It was unclear why the machines accepted these ballots on Election Day, but rejected them during the recount. That this kind of thing happened at the recount also means that it could have happened on Election Day: an unknown number of ballots may have been rejected by the machines and thereby judged ambiguous when, in fact, there was no apparent reason why voter intent should have been questioned. In those cases where the elector was not there to remake the ballot or refused to remark it, the ballot would have been considered declined. Formal indefiniteness of outcome is here, as always, overcome by substantive human fiat.

A further concern that arose during the recount was that there were three occasions when the tabulators ceased to function and were replaced with alternative machines. In contrast, when tabulators broke down on Election Day, the ballots were placed in a box ${ }^{9}$ or in a pile beside the tabulator ${ }^{10}$ and electors were told the operator would feed them into the machine once a replacement machine was provided or the machine was fixed. The elector was no longer at the polling station when the ballots were fed into

${ }_{9}^{9}$ This is according to an email message from an elector in Ward 9 who was concerned about seeing his ballot being placed in a box to be fed into the machine at a later time when the ma-

${ }^{10}$ This is according to a hand written letter from an elector in
Ward 9 who was concerned about the pile of ballots that was Ward 9 who was concerned about the pile of ballots that was
sitting beside the "counting machine" because the machine was not working. He was told to leave his "folded, marked ballot beside the machine and that it would be counted later." 
the machine, as they entrusted their ballot to the operator. Again, any ambiguous ballot from the box or the pile would automatically become a declined ballot because the elector was not there to remake the ballot.

In summary, during the recount, the ballots were re-fed into the machines and re-tabulated without a glitch. Because the ballots identified as ambiguous during the recount were re-made, the final result remained the same. In fact, the recount was realized in such a way that it was designed to reproduce the same result: Candidate A beat Candidate B by one vote. If the ballots that were identified as ambiguous during the recount had been treated the same way as ambiguous ballots on voting day, then they would have all been placed in the Declined ballot envelope and not counted. This shows the inability of the machines to replicate the process realized on Election Day. Human intervention was (and always is) not only required for mechanization to work but to be seen to have worked consistently.

\section{The Second Recount}

Scrutineers for Candidate B present at the first recount identified two over-voted ballots that showed, in their view, clear voter intent for said candidate. [The machine read these ballots as over-votes presumably because there were markings opposite two of the candidates' names instead of just one of the names. But, to the human, socialized eye one of the markings in each case could be seen to have been "crossed out" in favor of the other marking.] In keeping with Section 58. (1) of the MEA, Candidate B's team submitted an "application for order for re- count" which would allow for the manual inspection of the ballots in question.

\section{Section 58. (1) states that:}

[a] person who is entitled to vote in an election and has reasonable grounds for believing the election results to be in doubt may apply to the Superior Court of Justice for an order that the clerk hold a recount. [1996, c. 32, Sched., s. 58 (1); 2002, c. 17, Sched. D, s. 22 (1)]

The application was successful and a second recount was conducted. The tabulated election results indicated 40 over-voted ballots for Ward 9 councilor. The judge ordered the clerk to look beyond the machine reading of the ballots in question and to determine voter intent through visual inspection. All of the ballots were to be removed from the ballot boxes and the over-voted ballots identified and inspected. The judge's order stated:

if the markings on any of those 40 ballots can show a clear intention to cast a sole vote for any one of the council candidates, even if the markings indicate that the voter has changed his or her preference, those ballots must be counted in favor of the candidate so determined by the Clerk and thus added to the tally previously declared by the Clerk, who will then determine what the final count is for each of the Ward 9 candidates.

All the ballots were removed from the boxes and fed into the tabulators. As the tabulators progressively identified the 40 over-voted ballots, they were set aside for further inspection. Inspection was done by the candidates (including any who ran for election in that ward and were present at the recount), their lawyers, the city clerk, and the city's lawyer. Each ballot was looked at and 5 "disputed" ballots were identified. They came to be identified as disputed ballots because upon "close inspection" voter intent could be "reasonably" determined by an appropriately socialized "reasonable man" (sic), but not by an "unsocialized" machine, which treated the markings in each case as an over-vote.

With the principal parties sitting around a square table in the middle of the room in City Hall set aside for the recount, and with the other involved parties sitting around the edge of the room, the first of the five ballots was disclosed. Candidate A's lawyer identified it as a clear vote for his client, Candidate B's lawyer identified it as a spoiled ballot, and the city clerk identified it as a spoiled ballot. In this fashion the first four ballots were dealt with: one candidate's lawyer would claim the ballot as a clear vote for his client, the other candidate's lawyer would say it was spoiled, and the clerk would say it was spoiled. The fifth and final case was different. On the fifth ballot, Candidate A's lawyer identified the ballot as a clear vote for his client, Candidate B's lawyer concurred with this assessment, and the clerk identified it as a spoiled ballot. This was the tipping point for Candidate B. From the point of view of the reasonable [person], it was clear at this point that Candidate B had actually lost by two votes, a result that was not, and will never be, recorded as such because the clerk identified all five disputed ballots as spoiled. While not to be found in the final recorded results of the recount, the visual inspection of the disputed ballots proved to be essential to ensure that voter intent be respected. Had the recount resulted in favor of Can- didate $B$, notwithstanding the clerk's determinations, a further, judicial recount would have been sought.

\section{Discussion: The Mechanization of Voter} Intent as a Social Production

The official election result remained unchanged through the two recounts, and was reported as such. This can be seen, and was seen in some quarters, as a vindication of the mechanized manner of counting votes through the use of optical scanning tabulators, and called into question the wisdom of Candidate B in pursuing the recounts. The topic of interest here, however, is not the advisability of seeking recounts, but the social production of a mechanized result, the all-too-human accomplishment of a non-human consistency. There are several aspects to this production.

First, it cannot be too stressed that voting and counting votes are human, social actions, however practiced, routinized, legislated, rule-bound, institutionalized, technologized, and mechanized they appear to be. Indeed, it is in just the way they have these features that they are human, social actions as Weber, Schütz, Winch and the "action" school of social theory, not to mention Austin and Searle, have been at pains to argue for over one hundred years. Putting marks on pieces of paper only makes sense in the context of a set of institutions that constitute such behaviors as meaningful actions in the first place (Eglin 1975; 1980; Coulter 2009).

But, secondly, this fundamental sociological idea extends to the sphere of machines and the mechanical as well. Not only are these technological things hu- 
man inventions with human consequences, having human uses and symbolizing such human ideas as divine design (Noble 1995: chap. 7; 2005:69-86), not only do they participate in socially organized courses of action (such as those that organize a factory floor, or office layout, or research laboratory, or space station, or living room), including human-computer interaction and vote counting - but they are social in a deeper sense as well. That is, it may be said that they are social objects in the sense that they are "socialized" by humans. They are enlivened (Suchman 2007), brought to life - not in the sense of robotics

- but in the way, say, we respond to their displays by saying they are "telling us something" (the number of over-votes, for example). That is, we "read" through their penciled or pixelated displays of marks and signs to the real-worldly, that is, social, facts we see them as reporting (Garfinkel, Lynch, and Livingston 1981). And that includes the "mechanical consistency" we see them as exhibiting, for what could be more human than the awe we feel before such a phenomenon. It is something we can trust, we feel, being other than us, mired as we are in our human unreliability and fickle judgment.

Thirdly, and finally, however, we can further articulate the preceding action-theoretical, interpretive, and phenomenological/ethnomethodological accounts of the social character of mechanization by turning briefly to some observations occasioned by symbolic interactionism and conversation analysis. At the end of the introduction, we proposed that the clerk could be seen to have acted according to some such rule as might be expressed in the catchphrase "machines don't lie." One advancing the claim that he followed such a rule (so as to be seen to be governed by it) could point to the various steps the clerk took during the first recount to preserve the integrity of the machine result of the original count; for example, problematic ballots that emerged in the first recount were re-made so that they were accepted by the machines, so guaranteeing an identical outcome. And in the second recount, his judgment of the five disputed ballots was not only the same in each case but also the same as the verdict rendered by the machines in the previous counts. It may then be said that he acted, in a sense, as the machines' representative, their mouthpiece. Since they could not speak for themselves, he would speak for them. In so doing, he could also be seen as not just defending his professional reputation - after all, the reliable operation of such machines was his responsibility - but acting in the same professional spirit and with the same professional expertise that had led him to support their use in the first place.

Nevertheless, it may be countered that the clerk's five successive determinations of "spoiled ballot" in the second recount were not simply the product of conformity to a pre-adopted rule, as an interactionist account might have it, but the result of genuine, independent scrutiny of each case; that each ballot was adjudged by him to be spoiled was because, after all, to his reasoned, fair, and in-good-faith gaze they were spoiled. There is, however, a further feature of the "rolling out" of the clerk's judgments that is relevant here. The utterances that conveyed these judgments did not occur in a vacuum, but in the course of a sequence of essentially three-party interaction with the candidates' lawyers. It may be called a "determining" sequence, the turns being partially pre-allocated in that for each ballot one of the candidates' lawyers would go first, followed by the other lawyer, with the clerk going last in each case. Why is this significant?

As indicated above, the fifth case departed from the action pattern of the first four ballot adjudications. In the first four cases, the lawyers could be seen to be acting in an adversarial fashion, that is, as lawyers, finding for their clients and against their opponents by disagreeing with one another; their judgments could be seen to be category-bound actions (Sacks 1974:221-224 calls them "activities") of the category "lawyer." But, in the fifth and final case, Candidate B's lawyer, going second, could be seen to be continuing this practice (that is, acting adversarially as a lawyer in favor of his client), but by now agreeing with Candidate A's lawyer that the ballot did indeed record a vote for Candidate A. Against this now undisputed agreement between the two lawyers the clerk again said "spoiled." The lawyers' agreement, achieved by Candidate B's lawyer in the immediately preceding turn, now provided the interpretive means for making observable the clerk's unwavering subscription to his rule. The social facticity of his rule-governed actions was the joint product and interactional accomplishment of the methods of sequential organization and membership categorization of the participants in the recount determination itself. ${ }^{11}$

${ }^{11}$ To be clear, in invoking the category-bound character of the lawyers' actions, we are saying that it is the hallmark of the lawyers actions, we are saying that it is the hallmark of the
privately retained lawyer that they shall act in the best interprivately retained lawyer that they shall act in the best inter-
est of the client who has hired them: such actions and their accompanying disposition may then be said to be bound to the category "lawyer" as what lawyers do. Such category-bound predicates may then afford an interpretive means by which lawyers' actions can be identified as such. In disputed matters involving other parties, this means acting, and being seen to
act, "adversarially" that is, taking their client's side despite act, "adversarially," that is, taking their client's side despite
what they might otherwise think of the merits of the case at what they might otherwise think of the merits of the case at
hand. In this way the two lawyers in question produced "disagreements" over the voter intent displayed in the first four ballots, and "surprise" in the audience when "agreement"
The warrant for this last account, informed as it is by ethnomethodology and conversation analysis, is to be found in "next turn," that is, the subsequent judicial hearing for costs. Though the plaintiff (Candidate B) "lost” the recount, the judge, who had ordered that "if the markings on any of those 40 ballots can show a clear intention to cast a sole vote for any one of the council candidates...those ballots must be counted in favor of the candidate so determined by the Clerk," did not make the plaintiff liable for the City's costs. This anticipated, possible outcome was the context invoked and reached for in Candidate B's lawyer's agreeing turn in the fifth case of the determination sequence (cf. Heritage 1984:242-243).

In the end, the mechanization of voter intent is seen to be, after Garfinkel, the artful, achieved, ongoing product of the everyday practices of organized settings of ordinary social affairs populated by actors going about the business of their occupational lives (so as to make visible to one another how their actions are) in accordance with the mores (see Coulter 2009). ${ }^{12}$

was produced in the case of the fifth ballot. Only in light of such category-bound predicates, and what Garfinkel (1967:41) calls the "'retrospective-prospective' sense of a present ocbe seen to be motivated by his concern for the interests of his client in the anticipated hearing for costs. His action may be seen as directed by the desire to make visible the clerk's unwavering subscription to his rule, arguably in contravention of the judge's ruling enjoining him (the clerk) to identify voter intent if he can, and thus making him liable for at least his side's (that is, the City's) costs. In this way not only the "disagreeing" but also the "agreeing" actions of Candidate B's lawyer may be seen as adversarial, that is, motivated by
his desire to be acting in his client's interests. ${ }^{12}$ Thesire to be acting in his client's interests.

${ }^{12}$ The authors wish to express their appreciation for the helpful ideas. For entry into his voluminous writings on matters germane to the subject under investigation here, see the website http://www.sharrockandanderson.co.uk. 


\section{References}

Allers, Maarten A. and Peter Kooreman. 2009. “More Evidence of the Effects of Voting Technology on Election Outcomes." Public Choice 139:159-170.

Association of Municipal Managers, Clerks and Treasurers of Ontario (AMCTO). 2011. 2010 Ontario Municipal Elections AMCTO Post-Election Survey: Final Report. Retrieved June 27, 2011 (http://www.amcto.com/imis15/CMDownload.aspx?ContentKey=99240a92-a6b0-49d8-a896-41b43682f62a\&ContentItemKey=234785ea-b3c8-42d0-9bb5-9635bac7ef3c).

Balzarotti, Davide et al. 2010. "An Experience in Testing the Security of Real-World Electronic Voting Systems." IEEE Transactions on Software Engineering 36(4):453-473.

Canada Elections Act. 2000. Retrieved May 15, 2011 (http:// laws-lois.justice.gc.ca/eng/acts/E-2.01/FullText.html).

Card, David and Enrico Moretti. 2007. “Does Voting Technology Affect Election Outcomes? Touch-screen Voting and the 2004 Presidential Election." Review of Economics and Statistics 89(4):660-673.

Chapman, Debra. 2012. "The Mechanization of Voter Intent." Paper presented at the annual meeting of the Canadian Political Science Association, Edmonton.

City of Midwest. 2010. Managing Deputy Returning Officer's Handbook: 2010 Municipal Election, October 25.

City of Midwest. 2010. Recount of Ballots Cast for Councillor, Ward 9: 2010 Municipal Election, November 3.

Clerk's Affidavit. 2010. Court File \#C-1016-10. Ontario Superior Court of Justice. City of Midwest, December 8.

Coulter, Jeff. 2009. "Rule-Following, Rule-Governance and Rule-Accord." Journal of Classical Sociology 9(4):389-403.

Dee, Thomas S. 2007. “Technology and Voter Intent: Evidence from the California Recall Election." Review of Economics and Statistics 89(4):674-683.
Eglin, Peter. 1975. “What Should Sociology Explain - Regularities, Rules or Interpretations?" Philosophy of the Social Sciences 5(4):377-391.

Eglin, Peter. 1980. Talk and Taxonomy. Amsterdam: John Benjamins.

Eglin, Peter. 1987. “The Meaning and Use of Official Statistics in the Explanation of Deviance." Pp. 184-212 in Classical Disputes in Sociology, edited by R. J. Anderson, J. A. Hughes, W. W. Sharrock. London: Allen and Unwin.

Garfinkel, Harold. 1967. Studies in Ethnomethodology. Englewood Cliffs, NJ: Prentice-Hall.

Garfinkel, Harold. 2002. Ethnomethodology's Program: Working Out Durkheim's Aphorism. Lanham, MD: Rowman and Littlefield.

Garfinkel, Harold, Michael Lynch, and Eric Livingston. 1981 "The Work of a Discovering Science Constructed with Materials from the Optically Discovered Pulsar." Philosophy of the Social Sciences 11(2):131-158

Gatien, Daniel. 2012. Letter to Honourable Kathleen Wynne: “Re: Reforms to the Municipal Elections Act," February 24. Retrieved August 12, 2012 (https://www.amcto.com/imis15/CMDownload. aspx?ContentKey=c3fa8702-0109-4e71-b62d-2185ed70f396\&ContentItemKey=c57186de-b903-4802-80d8-f2c909dc123d).

Heritage, John. 1984. Garfinkel and Ethnomethodology. Cambridge: Polity Press

Hughes, John A. and Wes W. Sharrock. 2007. Theory and Methods in Sociology: An Introduction to Sociological Thinking and Practice. Basingstoke: Palgrave Macmillan.

Hursti, Harri. 2005. The Black Box Report. Security Alert: July 4 2005. Critical Security Issues with Diebold Optical Scan Design. Black Box Voting Company. Retrieved February 24, 2011 (http:// www.blackboxvoting.org/BBVreport.pdf).

Lott, John R. Jr. 2009. “Non-voted Ballots, the Cost of Voting, and Race." Public Choice 138:171-197.
McMenemy, John. 1995. The Language of Canadian Politics: A Guide to Important Terms and Concepts. Revised Edition. Waterloo: Wilfrid Laurier University Press.

Mebane, Walter R. Jr. 2008. “Machine Errors and Undervotes in Florida 2006: Revisited." Prepared for the Symposium, “How We Vote," Institute of Bill of Rights Law, William and Mary School of Law, Williamsburg, Virginia. Retrieved March 10, 2011 (http:// www-personal.umich.edu/ wmebane/howpaper2.pdf).

Noble, David F. 1995. Progress Without People: New Technology, Unemployment, and the Message of Resistance. Toronto: Between the Lines.

Noble, David F. 2005. Beyond the Promised Land: The Movement and the Myth. Toronto: Between the Lines.

Ontario Election Act. 1990. Retrieved January 12, 2011 (http:// www.e-laws.gov.on.ca/html/statutes/english/elaws_statutes_90e06_e.htm\#BK139).
Ontario Municipal Elections Act. 1996. Retrieved January 12, 2012 (http://www.e-laws.gov.on.ca/html/statutes/english/ elaws_statutes_96m32_e.htm).

Russell, W. D. (Rusty). Q. C. 1980. “Is the Ballot Valid or Invalid?" Municipal World 90(9):232-237.

Sacks, Harvey. 1974. “On the Analyzability of Stories by Children." Pp. 216-232 in Ethnomethodology: Selected Readings, edited by R. Turner. Harmondsworth: Penguin.

Searle, John. 1969. Speech Acts: An Essay in the Philosophy of Language. London: Cambridge University Press.

Suchman, Lucy. 2007. Human-Machine Reconfigurations: Plan and Situated Actions. $2^{\text {nd }}$ ed. Cambridge: Cambridge University Pres.

Winch, Peter. 2008. The Idea of a Social Science and its Relation to Philosophy. $3^{\text {rd }}$ ed. London, New York: Routledge Classics. 